\title{
Erratum to: Case report: central venous catheterization via internal jugular vein with associated formation of perioperative venous thrombosis during surgery in the prone position
}

\author{
Kimito Minami $\cdot$ Miki Iida $\cdot$ Hiroki Iida
}

Published online: 20 March 2012

(C) Japanese Society of Anesthesiologists 2012

Erratum to: J Anesth

DOI 10.1007/s00540-012-1329-2

The first author's name was shown incorrectly as Kimito Mimami. The correct name is Kimito Minami.

The online version of the original article can be found under doi:10.1007/s00540-012-1329-2.

K. Minami $(\varangle) \cdot$ M. Iida $\cdot$ H. Iida Department of Anesthesiology and Pain Medicine, Gifu University Graduate School of Medicine,

1-1 Yanagido, Gifu, Gifu 501-1194, Japan

e-mail: nann_5115@ybb.ne.jp 